\title{
Ashley Spear Advances Data-Driven Approaches to Materials Research
}

\section{Lynne Robinson}

In the July 2018 JOM technical topic, Data-driven Material Investigations: Understanding Fatigue Behavior, Ashley Spear's interest and engagement in this area was strongly evident. In addition to serving as a guest editor, she co-authored two articles-"Data-Driven Materials Investigations: The Next Frontier in Understanding and Predicting Fatigue Behavior" and "Data-Driven Correlation Analysis between Observed 3D FatigueCrack Path and Computed Fields from High-Fidelity, Crystal-Plasticity, FiniteElement Simulations".

"In my opinion, one of the current and most pressing challenges has to do with our ability to manage and interpret the vast amount of data that we, as a community, are able to generate both experimentally and computationally," Spear said, in discussing the topic. "This challenge presents an exciting possibility of using data-driven approaches, like machine learning, to help identify patterns and establish quantitative process-structure-property-performance links. There is a lot of great work going on in this area, and this $J O M$ topic deals with this exact set of challenges and opportunities."

Currently an assistant professor of mechanical engineering at the University of Utah, Spear points to her very first project as a graduate student at Cornell University for sparking her interest in data-driven techniques. "It was a NASA-funded project to enable real-time strength predictions of aircraft components subjected to large-scale damage by using fracture simulations and artificial neural networks," Spear recalled. "I really enjoyed the work, and when it ended, I had the opportunity to explore crack propagation at much smaller length scales. As a result of my involvement in these two projects, I continue to be very interested in linking the microstructure scale with the scale of engineering components to help improve predictions of structural failure."
As the director of the university's Multiscale Mechanics \& Materials Laboratory, Spear has advanced the use of data-driven techniques to help leverage, integrate, and glean information from experiments and models. "This is an exciting area of research that I hope to continue to pursue with my students," she said. She noted that the focus of her lab's work involves integrating 3D imaging data with 3D numerical simulation to understand and predict the evolution of failure in a variety of structural materials.

Spear's dedication and excellence in her field has already earned wide recognition, including an Air Force Office of Scientific Research Young Investigator Award in 2015 and a National Science Foundation Early Career Award in 2018. She has also shared her enthusiasm and knowledge with her professional community as an active TMS volunteer.

"My involvement with TMS has helped me tremendously in meeting new people, expanding my network, and establishing fruitful collaborations with other researchers in the field," Spear said.

As she looks forward, Spear is quick to acknowledge the lasting impact of her mentors, stretching back to her undergraduate days at the University of Wyoming. She specifically highlights the influence of Anthony Ingraffea, her graduate advisor and professor as "the greatest influence in my career. He showed me how to be a good researcher, educator, and human being," she said. She also notes that an early collaboration with Robert Suter, professor at Carnegie Mellon University, "had a profound impact on my career path," for which she is grateful.

The lessons she has learned through these experiences informs the advice she offers to professionals just starting out on their career journeys. "Surround yourself with good people who do good work," she said. "Seek mentorship and don't be afraid to ask forand offer-help" 